\title{
Fenologia de uma comunidade arbórea em cerrado sentido restrito, Barra do Garças, MT, Brasil ${ }^{1}$
}

\author{
Flávia Richelli Pirani² ${ }^{2}$ Maryland Sanchez ${ }^{3,4}$ e Fernando Pedroni ${ }^{3}$
}

Recebido em 17/04/2008. Aceito em 31/03/2009

\begin{abstract}
RESUMO - (Fenologia de uma comunidade arbórea em cerrado sentido restrito, Barra do Garças, MT, Brasil). Analisamos a fenologia vegetativa e reprodutiva procurando relacionar mudanças nas fenofases com variáveis abióticas (precipitação, temperatura e fotoperíodo) e investigamos a ocorrência de sazonalidade. A região apresenta verão chuvoso (outubro-abril) e inverno seco (maio-setembro). Entre out/2005 e set/2007, 1.221 indivíduos pertencentes a 84 espécies foram monitorados mensalmente quanto a presença/ausência e intensidade das fenofases queda foliar, brotamento, floração e frutificação. A maioria das espécies apresentou estratégia fenológica vegetativa decídua (44\%) ou brevidecídua (16\%). A queda foliar foi correlacionada negativa e significativamente com precipitação e fotoperíodo, apresentando data média em agosto. O brotamento apresentou correlação positiva com temperatura média mensal. Floração e frutificação ocorreram nos dois anos em 69 espécies. Houve maior concentração de flores nos meses de maior estresse hídrico (jul-ago). A frutificação de espécies zoocóricas ( $70 \%$ das espécies na área) ocorreu de forma contínua, sendo correlacionada negativamente com precipitação e positivamente com temperatura. A frutificação das anemocóricas ocorreu nos meses mais secos. Nossos resultados sugerem padrões fenológicos sazonais, sendo que na transição entre estações seca e chuvosa ocorreu maior atividade vegetativa e reprodutiva. Esses padrões fenológicos têm sido comumente encontrados no cerrado brasileiro e sugerem que a época de dispersão, germinação de sementes e de estabelecimento de plântulas é um fator importante para sincronizar a maturação dos frutos no início da estação chuvosa.
\end{abstract}

Palavras-chave: brotamento, floração, frutificação, queda foliar, savana neotropical, sazonalidade climática

ABSTRACT - (Phenology of a tree community in a cerrado sensu stricto, Barra do Garças, Mato Grosso state, Brasil). We observed leaf and reproductive phenology and analyzed the relationship among phenophases and abiotic variables (rainfall, temperature and photoperiod) and investigated the occurrence of seasonality. The local climate is characterized by marked wet (October-April) and dry seasons (May-September). From October 2005 to September 2007, 1221 individuals of 84 species were observed monthly for changes in leaf fall, leaf flush, flowering and fruiting. Deciduous (44\%) and brevideciduous $(16 \%)$ species were predominant in the area. The leaf fall was negatively correlated with rainfall and photoperiod, with mean date in August. Leaf flush was positively correlated with temperature. Flowering and fruiting were observed in both years for 69 species. Flowering occurred mainly at the dry season (July-August) and was inversely correlated with rainfall. The zoochorous species were predominant in the community. Fruiting of anemochorous species was inversely correlated with rainfall. Fruiting of zoochorous species occurred continually throughout the year and was negatively correlated with rainfall and positively with temperature. Our results suggest overall seasonal patterns with peaks of vegetative and reproductive activity occurring between dry and wet seasons. These phenological patterns have been demonstrated to be common in Brazilian savanna, and suggest that the timing of seed dispersal, germination and young seedling development is a major factor responsible for synchronized ripening of fruits at the beginning of the rainy season.

Key words: climatic seasonality, flowering, fruiting, leaf fall, leaf flush, neotropical savanna

\section{Introdução}

Nas savanas tropicais, padrões temporais de crescimento e reprodução das plantas estão ligados à sazonalidade climática (Williams et al. 1997). Tradicionalmente as mudanças fenológicas de plantas tropicais foram consideradas resultantes principalmente da duração e intensidade da seca sazonal, já que, em baixas latitudes, a variação anual da temperatura e do fotoperíodo é pequena (Borchert 1996). No entanto, estudos recentes têm apontado o fotoperíodo como importante desencadeador das fenofases em ambientes tropicais (Morellato et al. 2000; Borchert et al. 2006; Stevenson et al. 2008). Se as relações causais entre seca sazonal e fenologia das árvores são verdadeiras, então as variações dos padrões fenológicos deverão ser indicadoras da sazonalidade ambiental (Borchert 1996). Por outro lado, produzir folhas, flores e frutos nessa estação pode ser um indicativo da disponibilidade de água no solo para as plantas durante a seca sazonal (Franco 2002; Oliveira et al. 2005; Lenza \& Klink 2006).

Numerosos estudos fenólogicos, tanto em savanas (Mantovani \& Martins 1988; Gouveia \& Felfili 1998; Batalha \& Mantovani 2000; Batalha \& Martins 2004; Munhoz \& Felfili
2005; Lenza \& Klink 2006; Tannus et al. 2006; Munhoz \& Felfili 2007) como em florestas tropicais (Morellato et al. 2000; Reys et al. 2005; Marchioretto et al. 2006; Yamamoto et al. 2007; O'Brien et al. 2008) têm apontado questões importantes em relação ao funcionamento dos ecossistemas, tais como magnitude da deciduidade, grau de sincronia entre as principais fenofases e causas proximais e finais dos eventos fenológicos (Williams et al. 1997).

Uma característica marcante da vegetação lenhosa do cerrado é a ocorrência de diferentes grupos fenológicos em relação à produção e queda de folhas (Franco et al. 2005; Lenza \& Klink 2006; Araújo \& Haridasan 2007). Tem sido encontrado que, com o aumento da severidade da estação seca, ocorre maior proporção de espécies decíduas, sendo que a queda foliar ocorre durante essa estação (Reich 1995; Williams et al. 1997) e o brotamento, florescimento e frutificação podem ocorrer de maneira menos sazonal, tanto na estação seca como na chuvosa (Gouveia \& Felfili 1998; Batalha \& Mantovani 2000).

O desenvolvimento sazonal de espécies arbóreas tem grande influência sobre populações animais (Borchert 1996). Os ciclos fenológicos podem ser ajustados pela competição

\footnotetext{
1 Parte da dissertação de mestrado da primeira Autora

2 Programa de Pós-Graduação em Ecologia e Conservação da Biodiversidade. Universidade Federal de Mato Grosso, Cuiabá, MT, Brasil

3 Universidade Federal de Mato Grosso, Instituto Universitário do Araguaia, Pontal do Araguaia, MT, Brasil

Autor para correspondência: maryland@ufmt.br
} 
entre polinizadores e também dispersores de sementes que dependem dos recursos oferecidos pelas plantas. Por outro lado, os padrões de frutificação de espécies anemocóricas estão mais fortemente relacionados às condições ambientais favoráveis para a dispersão dos diásporos (Frankie et al. 1974; Morellato et al. 1989).

Este trabalho descreve, pela primeira vez, a fenologia das folhas, flores e frutos de uma área de cerrado no estado de Mato Grosso. As seguintes perguntas nortearam esse estudo: 1) Quais são as estratégias fenológicas vegetativas e o padrão de freqüência de florescimento e frutificação das espécies estudadas? 2) Quais são as variáveis abióticas com maior potencial para desencadear as diferentes fenofases? 3) As diferentes fenofases apresentam ritmos sazonais? Para responder essas perguntas analisamos o comportamento fenológico vegetativo e reprodutivo das espécies arbóreas presentes na comunidade de cerrado sentido restrito no Parque Estadual da Serra Azul, procurando relacionar as variações nas fenofases com variáveis abióticas (precipitação pluviométrica, temperatura e fotoperíodo). Como no cerrado há forte sazonalidade climática, esperamos encontrar predomínio de variações fenológicas sazonais na vegetação estudada. Em função das variações hídricas impostas pela sazonalidade no cerrado, esperamos ainda encontrar maiores proporções de espécies com estratégia fenológicas vegetativas decíduas e brevidecíduas do que espécies sempre-verdes. Finalmente esperamos encontrar que espécies com dispersão por vetores abióticos apresentem fenologia com maior correlação com variáveis abióticas e maior concentração nos períodos mais favoráveis à dispersão. Por outro lado, para as espécies cuja dispersão é realizada por agentes bióticos, esperamos menor relação com variáveis abióticas e um padrão de floração e frutificação mais contínuo ao longo do ano, permitindo a oferta constante de recursos para polinizadores e frugívoros.

\section{Material e métodos}

O estudo foi conduzido em cerrado sentido restrito, a $562 \mathrm{~m}$ de altitude, localizado no Parque Estadual da Serra Azul (PESA) (15 $51^{\circ}$ 'S e $52^{\circ} 16^{\prime}$ W), município de Barra do Garças na região do Vale do Rio Araguaia. O Parque Estadual da Serra Azul possui uma área de 11.002 ha e representa uma importante Unidade de Conservação na região leste do estado de Mato Grosso, incluindo em sua área diversas fitofisionomias do cerrado brasileiro, tais como matas de galeria, matas semidecíduas, cerrado sentido restrito, cerrado rupestre e veredas (FEMA 2000). As famílias mais ricas na área de estudo são Leguminosae, Myrtaceae, Annonaceae, Apocynaceae e Malpighiaceae. As espécies mais abundantes são Buchenavia tomentosa, Byrsonima cocolobifolia, Davilla elliptica, Kielmeyera rubriflora, Licania humilis, Mouriri elliptica, Mezilaurus crassiramea, Myrcia multiflora e Ouratea spectabilis (Barbosa 2006).

O clima da região caracteriza-se por duas estações bem definidas: uma chuvosa (outubro a abril) e outra seca (maio a setembro) (Fig. 1A). A precipitação média anual foi $1528 \mathrm{~mm}$, e a temperatura média $25,5^{\circ} \mathrm{C}$ no período entre 1995 a 2005 (Fig. 1A). Durante o período de estudo, a precipitação média anual foi $1447 \mathrm{~mm}$ e foram observadas duas estações secas e duas chuvosas. A estação seca de 2007 iniciou-se em abril, um mês antes que em 2006. A temperatura média mensal foi $25,2^{\circ} \mathrm{C}$ durante o período de estudo, sendo setembro de 2007 o mês com temperatura média mais elevada $\left(28,1^{\circ} \mathrm{C}\right)$, e maio de 2006 o mês com temperatura média

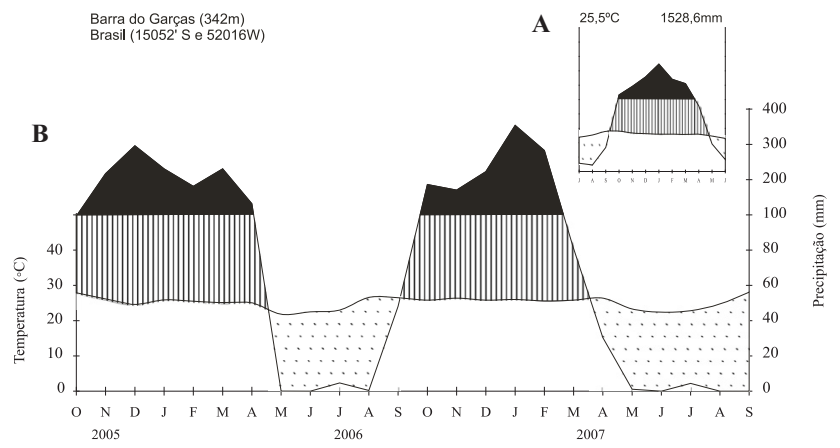

Figura 1. (A) Diagrama climático para a região de Barra do Garças, MT, Brasil, no período de 1995 a 2005, segundo o modelo de Walter (1986). (B) Dados climáticos para o período de estudo. A curva inferior mostra a temperatura média mensal; na curva superior, a precipitação mensal total. A zona preta representa períodos super úmidos, com precipitação superior a $100 \mathrm{~mm}$ por mês. Zona com traços: período úmido; zona pontilhada: período seco. Acima, nos gráficos, são mostradas a altitude do local onde está a estação meteorológica, temperatura média anual e precipitação $(\mathrm{mm})$.

mais baixa $\left(21,8^{\circ} \mathrm{C}\right)$ (Fig. 1B). Os dados climáticos foram registrados na estação meteorológica localizada a $15 \mathrm{~km}$ do local de estudo e fornecidos pela Empresa Brasileira de Infra-Estrutura Aeroportuária.

Foi estudada a fenologia de 1.221 indivíduos arbóreos pertencentes a 39 famílias e 84 espécies em intervalos mensais, no período de outubro de 2005 a setembro de 2007 . Quarenta e nove (58,3\%) espécies foram monitoradas com cinco ou mais indivíduos (chegando até 106 indivíduos), 22 (26,2\%) com dois a quatro indivíduos e $13(15,5 \%)$ com um único indivíduo. O número de indivíduos de cada espécie observada variou em função da densidade encontrada no PESA já que foram incluídos todos os indivíduos (DAS $\geq 5 \mathrm{~cm}$ ) amostrados nas parcelas estudadas por Barbosa (2006). Para cada indivíduo amostrado foi registrada, visualmente com auxílio de binóculo, a presença ou ausência das fenofases: queda de folhas, brotamento, floração (botões e antese) e frutificação (frutos imaturos e frutos maduros) (conforme Morellato et al. 1989). Para cada indivíduo, a intensidade das fenofases foi estimada em escala semi-quantitativa com quatro classes de porcentagem de $25 \%$ cada (Fournier 1974).

As espécies foram classificadas em grupos fenológicos vegetativos, os quais foram definidos pelo tempo de ocorrência das fenofases queda foliar e brotamento, assim como a intensidade da deciduidade nos indivíduos. As espécies sempre-verdes com renovação contínua (SVC) são representadas por espécies que substituem suas folhas velhas pelas novas continuamente durante o ano, sem uma época ou data definida. As espécies sempre-verdes com renovação sazonal (SVS) produzem folhas novas antes ou juntamente com a perda das folhas velhas, desta forma quando as folhas velhas caem, a árvore já apresenta folhas novas ou maduras. As espécies brevidecíduas (BDC) permanecem totalmente sem folhas por um período igual ou inferior a um mês, enquanto as decíduas (DC) ficam totalmente sem folhas por períodos superiores a um mês (Franco et al. 2005; Lenza \& Klink 2006; Araújo \& Haridasan 2007).

As espécies também foram classificadas quanto à freqüência anual de eventos de floração e frutificação como: contínua (ocorrência esporádica ao longo do ano), sub-anual (mais de um evento por ano), anual (um evento a cada ano) e supra-anual (eventos em intervalos de dois anos ou mais), de acordo com Newstrom et al. (1994). Para classificar as espécies cujos indivíduos marcados e observados não floresceram ou frutificaram, informações fenológicas reprodutivas foram obtidas a partir de coletas feitas no PESA durante o período de estudo e que estão incorporadas no acervo do herbário UFMT - Unidade ICLMA. As síndromes de dispersão das espécies foram estabelecidas segundo a classificação de van der Pijl (1982) e com o auxílio da literatura (Batalha et al. 1997; Batalha \& Mantovani 2000). As espécies foram classificadas como: anemocóricas - dispersão pelo vento e zoocóricas - dispersão por animais.

Coeficientes de Correlação de Sperman $\left(r_{s}\right)$ foram calculados entre o número de espécies observadas mensalmente em cada fenofase e variáveis abióticas (precipitação total mensal, temperatura média mensal e fotoperíodo) (Zar 1998). Para a fenofase frutificação, foram feitas correlações com 
o número de espécies, pertencentes a cada síndrome de dispersão (zoocoria e anemocoria). Como as respostas fenológicas aos estímulos ambientais podem se manifestar rapidamente ou tardiamente, investigamos a relação entre as variáveis abióticas no mesmo mês, no primeiro e no segundo mês anterior aos eventos fenológicos. Procedemos uma análise exploratória dos dados e observamos que as correlações encontradas entre as fenofases e dados climáticos (precipitação e temperatura no período 1995-2005, Fig. 1A) apresentaram os mesmos padrões das correlações com os dados meteorológicos do período de dois anos estudados (2005-2007). Assim, apresentamos apenas os resultados das correlações com dados do período de estudo e consideramos válida a sua extrapolação para padrões fenológicos e sazonalidade climática.

Foram elaborados histogramas circulares com as distribuições de freqüências das espécies em cada fenofase para cada ano de observação (2005/6, 2006/7) em intervalos mensais com os 365 dias correspondendo a aproximadamente $360^{\circ}$, sendo o dia 01 de outubro considerado $0^{\circ}$ e cada período de observação de 30 dias correspondendo a $30^{\circ}$. Foram calculadas as datas médias (ângulo médio) de queda de folha, brotamento, floração e frutificação e concentração (r) das espécies em torno dessas datas médias, utilizando-se o teste Rayleigh (z) para distribuições circulares (Zar 1998). O comprimento do vetor relaciona-se com o valor de $\mathrm{r}$ (coeficiente de concentração), que varia de 0 a 1 , e a seta aponta para o ângulo médio (data média) da distribuição de frequêencias. Se o ângulo médio é significativo, conseqüentemente há alguma sazonalidade e a intensidade de concentração em torno do ângulo médio, indicado por $\mathrm{r}$, pode ser considerada uma medida do grau de sazonalidade (Morellato et al. 2000). Diferenças no comportamento fenológico observadas nos dois anos de estudos foram comparadas em relação às datas médias de cada fenofase por meio do teste F (Watson-Williams) (Zar 1998). Essas análises de dados circulares foram realizadas utilizando-se o programa ORIANA (Kovach 2007).

\section{Resultados}

Para as 84 espécies arbóreas monitoradas, as fenofases queda foliar, brotamento, floração e frutificação variaram em relação à duração e época de ocorrência. Em todos os meses, foram observadas espécies perdendo folhas, florescendo ou frutificando, enquanto espécies brotando não foram observadas em mai/06 e jul/07. A floração ocorreu em períodos curtos (um a dois meses) para 22 espécies $(26,2 \%)$ e foi longa (cinco ou mais meses) para 24 espécies $(28,6 \%)$. A frutificação durou de um a dois meses para 16 espécies $(19,0 \%)$ e cinco ou mais meses para 28 espécies $(33,3 \%)$. Nove espécies (10,7\%) não floresceram e onze (13,0\%) não frutificaram (Tab. 1).

Fenofases vegetativas - A maioria das espécies estudadas apresentou estratégia fenológica vegetativa decídua (44,1\%) ou brevidecídua (15,5\%) enquanto as $40,4 \%$ espécies restantes foram divididas em sempre-verdes com renovação sazonal $(20,2 \%)$ e sempre-verdes com renovação contínua $(20,2 \%)$. As espécies decíduas mais abundantes foram Buchenavia tomentosa e Ouratea spectabillis, as brevidecíduas foram Mezilaurus crassiramea e Eschweilera nana, as sempre-verdes com renovação sazonal Byrsonima coccolobifolia e Mouriri elliptica e, finalmente, as sempreverdes com renovação contínua foram Licania humilis e Miconia albicans (Tab. 1).

A queda foliar ocorreu com maior intensidade na estação seca, de agosto a setembro. Nesse período, foi observada queda foliar na quase totalidade das espécies (Fig. 2A). A intensidade do desfolhamento na comunidade foi maior no segundo ano, atingindo 91\% em setembro de 2007 (Fig.
2B) após a ocorrência de queimada na área. Nove espécies (10,7\% do total) contribuíram fortemente com a mudança foliar observada na comunidade devido às suas abundâncias (42,2\% dos indivíduos observados) e características decíduas ou brevidecíduas. Foram elas, em ordem decrescente de abundância, Buchenavia tomentosa, Ouratea spectabillis, Davilla elliptica, Myrcia multiflora, Kielmeyera rubriflora, Mezilaurus crassiramea, Psidium myrsinoides, Andira cujabensis e Eschweilera nana (Tab. 1). A queda foliar foi correlacionada negativa e significativamente com a precipitação e com o fotoperíodo, sendo que essas duas variáveis abióticas foram altamente correlacionadas $\left(\mathrm{r}_{\mathrm{s}}=0,88 ; \mathrm{p}\right.$ $<0,01)$. O número de espécies perdendo folhas foi mais fortemente correlacionado com os índices pluviométricos e fotoperíodo que ocorreram nos dois meses imediatamente anteriores do que com aqueles que ocorreram no próprio mês de observação da fenofase (Tab. 2). As datas médias encontradas nos dois anos de estudo foram significativas (teste Rayleigh ( $\mathrm{z}$ ), $\mathrm{p}<0,05)$, mas os coeficientes de concentração (r) foram baixos (Fig. $2 \mathrm{C}$ e Tab. 3), indicando fraca sazonalidade. No primeiro ano de observação a data média de queda foliar foi 19/08/06 enquanto no segundo ano, 04/08/07, mas essa diferença não foi estatisticamente significativa $(F=3,32 ; \mathrm{p}=0,07)$.

No início desse estudo (out/05), foi observada a presença de folhas novas em $78 \%$ das espécies estudadas (Fig. 2A). No ano seguinte, o pico de brotamento ( 54 a $40 \%$ das espécies) ocorreu em período similar (set-out/06), caracterizando a transição da estação seca para chuvosa como o período em que a vegetação apresenta um aspecto mais vicejante. Em setembro de 2007, ocorreu uma queimada na área e apenas $42 \%$ das espécies produziram folhas novas (Fig. 2A), sendo que a intensidade (10\%) dessa fenofase foi mais baixa em relação aos anos anteriores (Fig. 2B). Durante a transição da estação seca para chuvosa, as espécies mais abundantes na área, Buchenavia tomentosa, Ouratea spectabillis, Davilla elliptica, Myrcia multiflora, Kielmeyera rubriflora, Mezilaurus crassiramea, Psidium myrsinoides, Andira cujabensis e Eschweilera nana determinaram a mudança no aspecto decíduo da vegetação, uma vez que apresentaram alta intensidade de brotamento (50 a 100\% da copa com folhas novas), exatamente entre os meses setembro e novembro. Essa fenofase mostrou relação positiva e significativa com a temperatura do mês do evento e do mês anterior ao evento (Tab. 2). Nos dois anos de estudo, as datas médias para ocorrência do brotamento foram significativamente diferentes $(F$ $=22,11 ; \mathrm{p}<0,01)$, sendo que ocorreu uma antecipação de 33 dias na segunda data média. Os coeficientes de concentração $(\mathrm{r} \cong 0,5)$ nos dois anos indicaram que a comunidade exibiu um padrão mais sazonal para essa fenofase (Fig. 2D e Tab. 3).

Fenofases reprodutivas - Houve predomínio de espécies com eventos anuais de floração e frutificação ( $75 \%$ para ambas) (Tab. 1). Os picos de emissão de botões florais e antese ocorreram em meses com estresse hídrico em ambos os anos de estudo (jul-ago) (Fig. 3A, B). O número de espécies em 


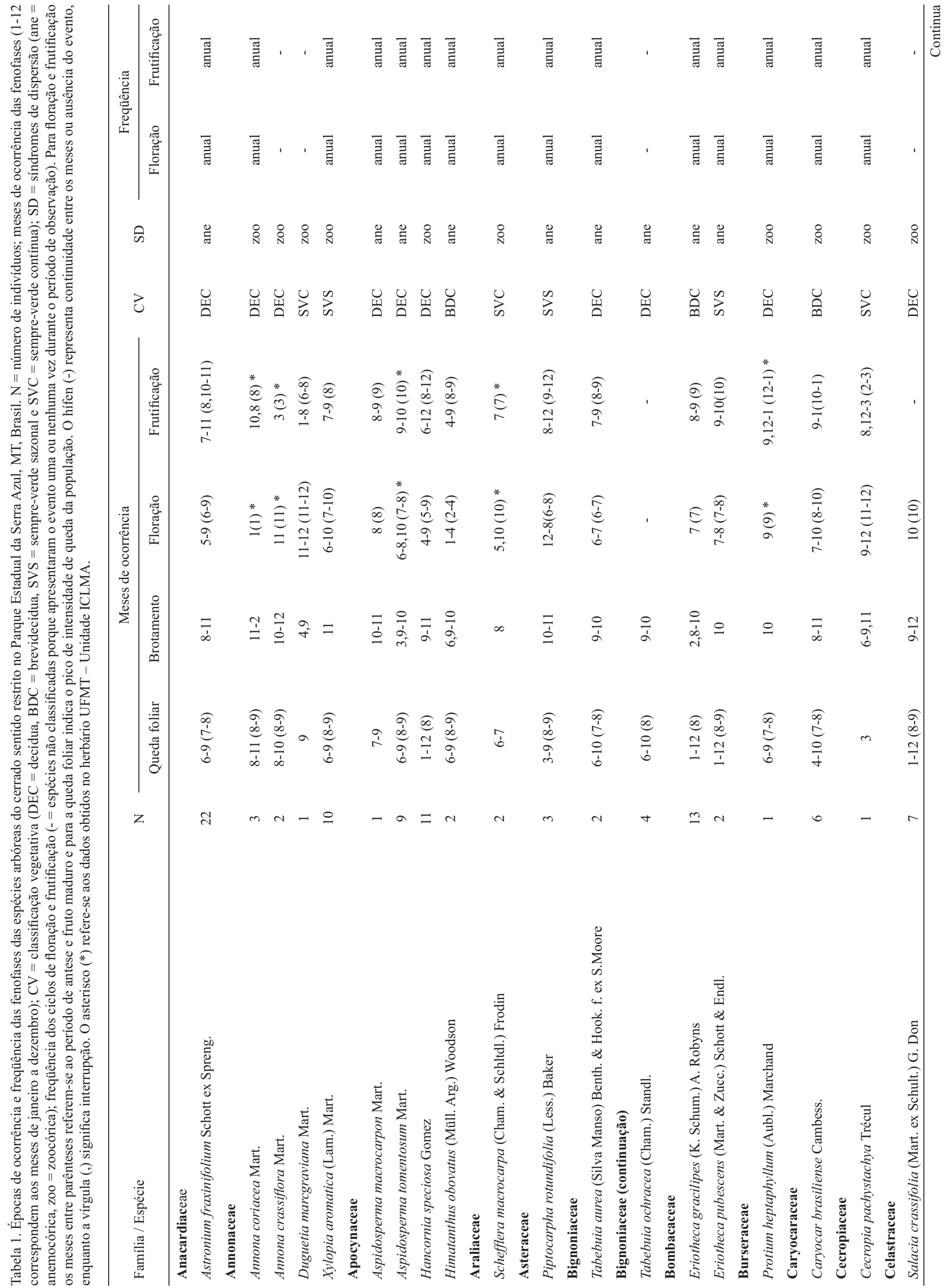




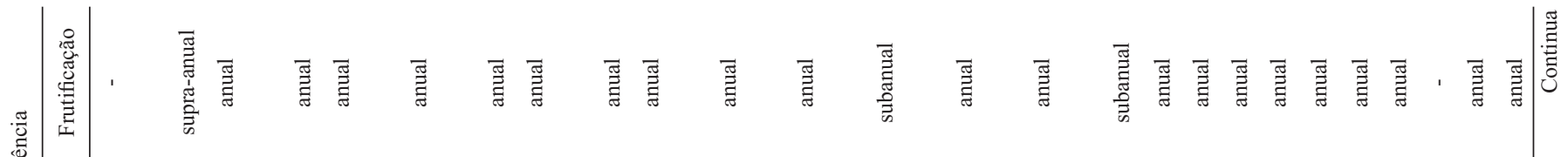

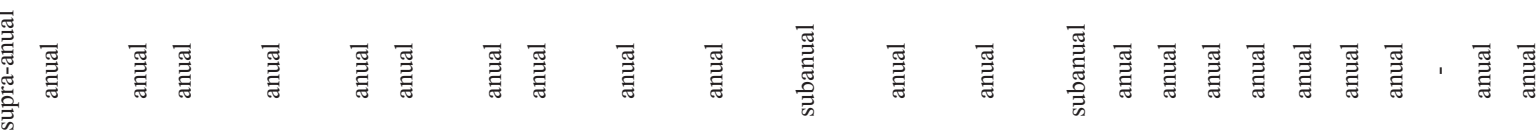
की

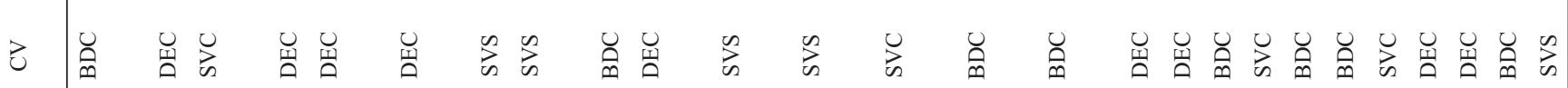

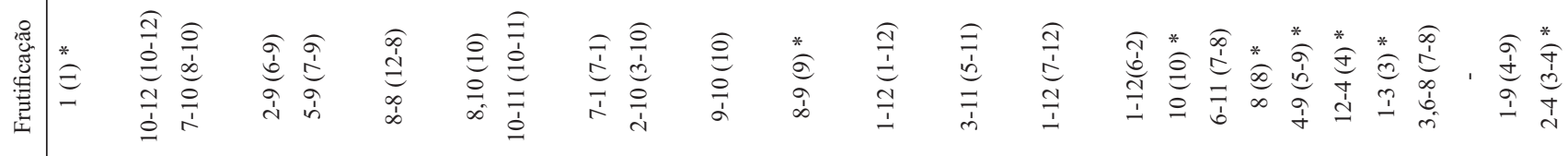

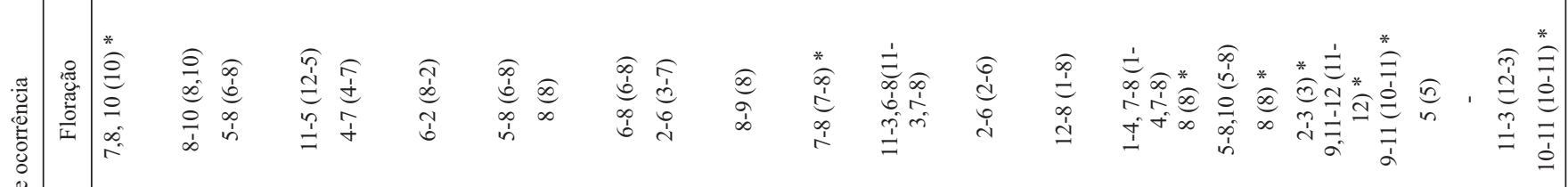

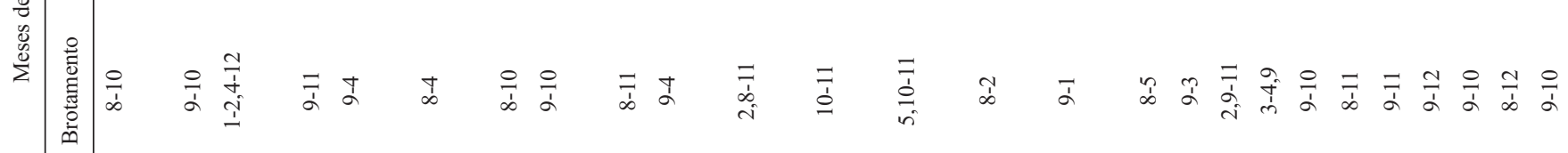

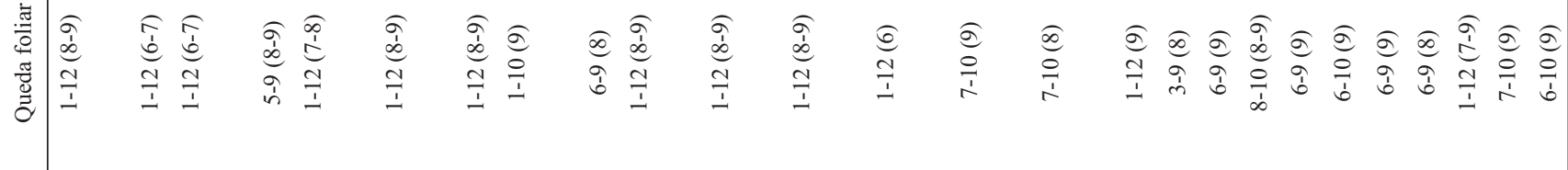

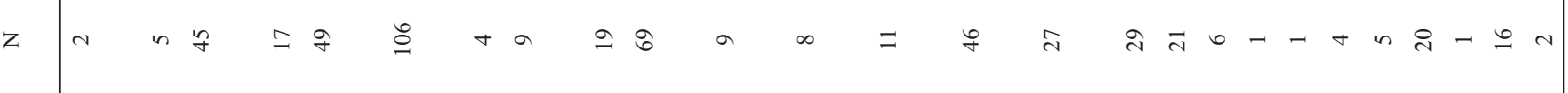

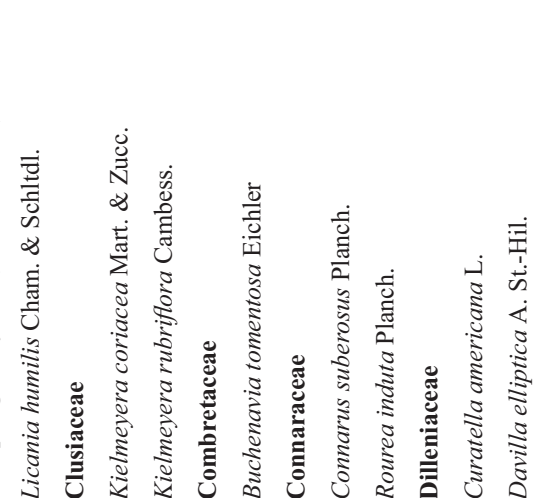

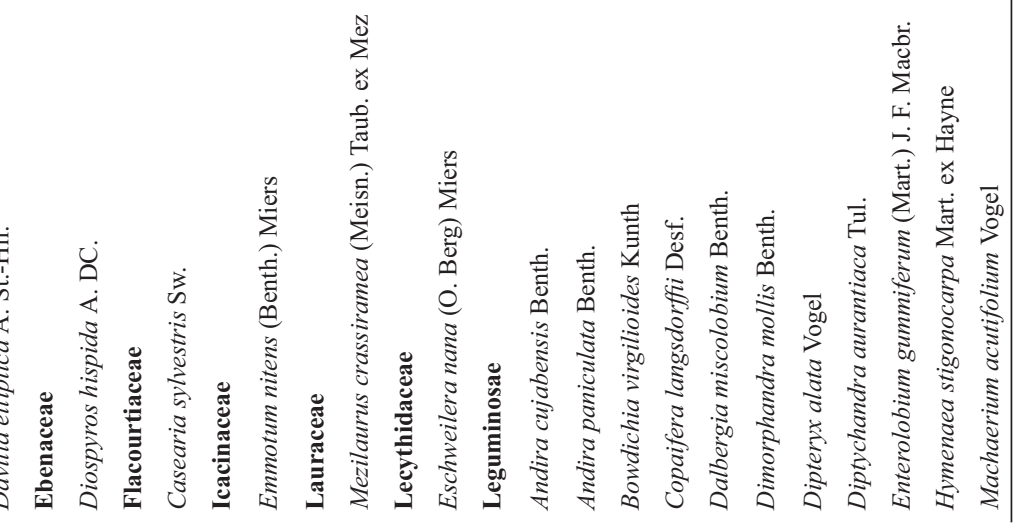




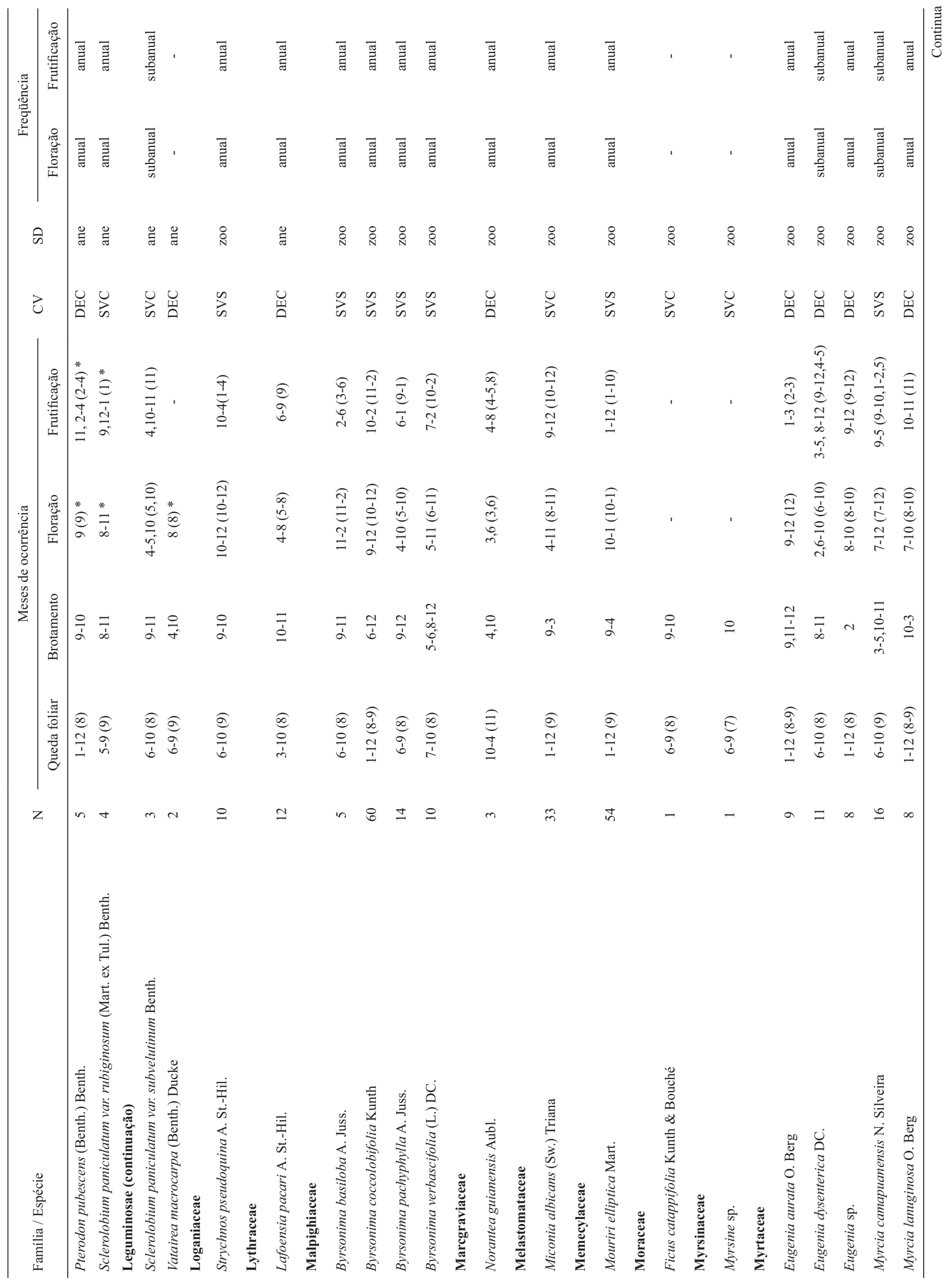




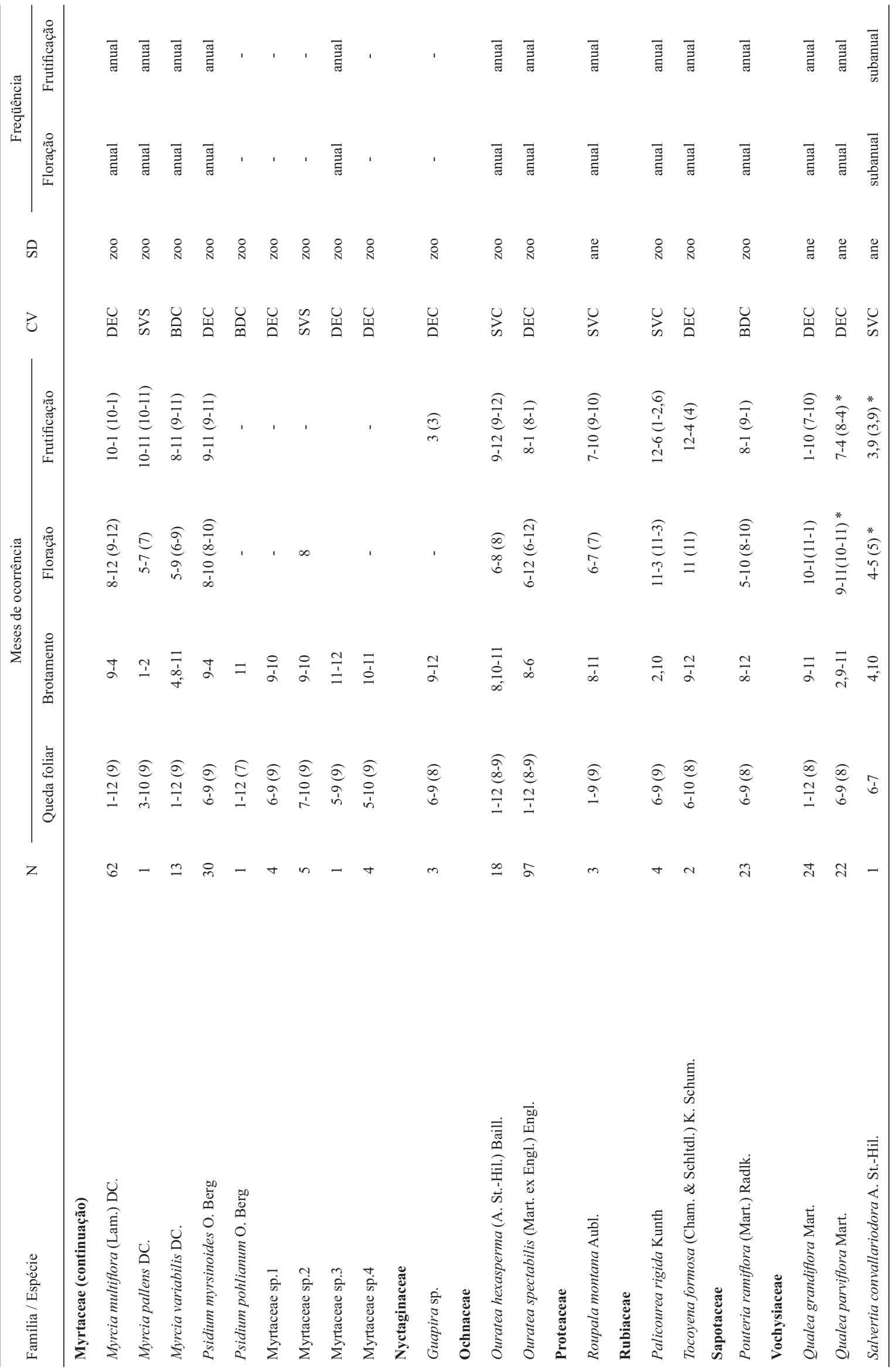


Tabela 2. Coeficientes de Correlação de Spearman ( $\mathrm{r}$ ) entre precipitação total mensal, temperatura média mensal, fotoperíodo e o número mensal de espécies nas fenofases brotamento, queda foliar, floração, frutificação. Para a fenofase frutificação, as correlações foram feitas separadamente para espécies anemocóricas e zoocóricas.

\begin{tabular}{|c|c|c|c|c|c|c|c|}
\hline \multirow{2}{*}{ Variável abiótica } & \multirow{2}{*}{ Fenofase } & \multicolumn{2}{|c|}{ Mês do evento } & \multicolumn{2}{|c|}{ Mês Anterior } & \multicolumn{2}{|c|}{2 Meses Anteriores } \\
\hline & & $\mathrm{r}$ & $\mathrm{p}$ & $\mathrm{R}$ & $\mathrm{p}$ & $\mathrm{r}$ & $\mathrm{p}$ \\
\hline \multirow{6}{*}{ Precipitação } & Queda Foliar & $-0,52$ & 0,01 & $-0,70$ & $<0,01$ & $-0,63$ & $<0,01$ \\
\hline & Brotamento & 0,22 & 0,30 & 0,01 & 0,98 & $-0,26$ & 0,22 \\
\hline & Floração & $-0,34$ & 0,10 & $-0,55$ & $<0,01$ & $-0,69$ & $<0,01$ \\
\hline & Frutificação & 0,07 & 0,74 & $-0,29$ & 0,17 & $-0,67$ & $<0,01$ \\
\hline & anemocóricas & $-0,39$ & 0,06 & $-0,60$ & $<0,01$ & $-0,78$ & $<0,01$ \\
\hline & zoocóricas & 0,28 & 0,19 & $-0,12$ & 0,56 & $-0,53$ & 0,01 \\
\hline \multirow{6}{*}{ Temperatura } & Queda Foliar & $-0,01$ & 0,95 & $-0,46$ & 0,02 & $-0,65$ & $<0,01$ \\
\hline & Brotamento & 0,61 & $<0,01$ & 0,55 & 0,01 & 0,09 & 0,67 \\
\hline & Floração & 0,02 & 0,91 & $-0,14$ & 0,51 & $-0,31$ & 0,14 \\
\hline & Frutificação & 0,56 & $<0,01$ & 0,40 & 0,05 & 0,04 & 0,85 \\
\hline & anemocóricas & 0,42 & 0,04 & $-0,01$ & 0,96 & $-0,36$ & 0,08 \\
\hline & zoocóricas & 0,53 & 0,01 & 0,51 & 0,01 & 0,19 & 0,39 \\
\hline \multirow{6}{*}{ Fotoperíodo } & Queda Foliar & $-0,46$ & 0,02 & $-0,66$ & $<0,01$ & $-0,70$ & $<0,01$ \\
\hline & Brotamento & 0,45 & 0,03 & 0,17 & 0,43 & $-0,19$ & 0,37 \\
\hline & Floração & $-0,58$ & $<0,01$ & $-0,79$ & $<0,01$ & $-0,76$ & $<0,01$ \\
\hline & Frutificação & 0,35 & 0,08 & $-0,12$ & 0,54 & $-0,59$ & $<0,01$ \\
\hline & anemocóricas & $-0,14$ & 0,52 & $-0,56$ & $<0,01$ & $-0,81$ & $<0,01$ \\
\hline & zoocóricas & 0,51 & 0,01 & 0,07 & 0,74 & $-0,40$ & $<0,01$ \\
\hline
\end{tabular}

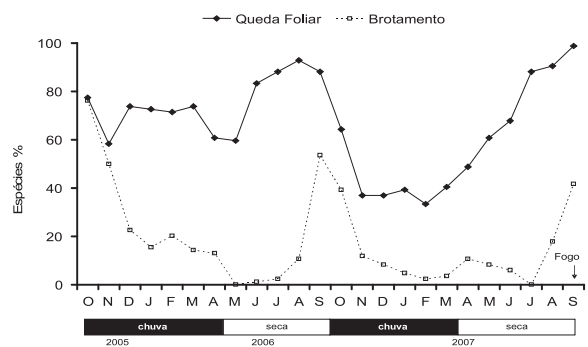

A
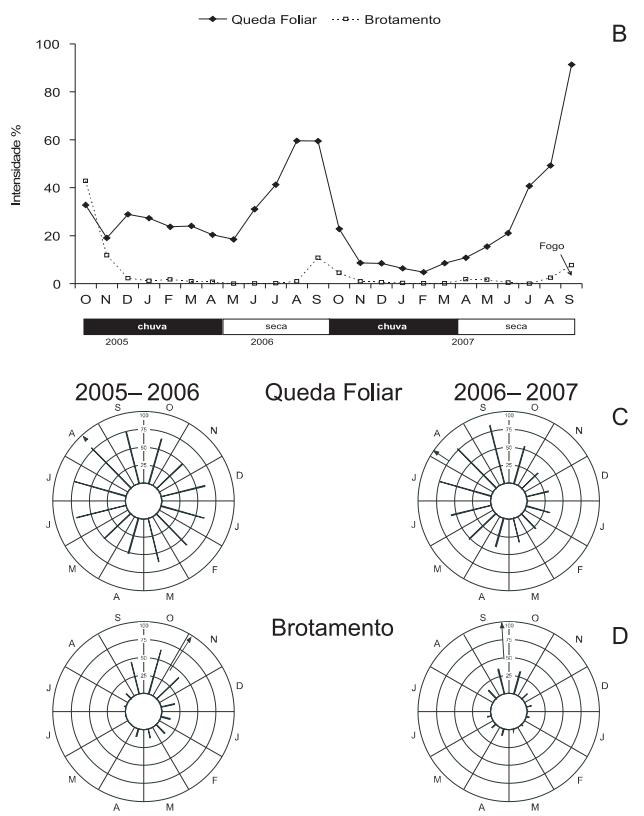

Figura 2. Porcentagem de atividade (A), e de intensidade (B) de brotamento e queda foliar no PESA, Barra do Garças, MT, Brasil. Histograma circular de freqüência relativa mensal de espécies em queda foliar (C) e brotamento (D); a seta indica a data média de ocorrência da fenofase e o comprimento do vetor, a concentração das espécies em torno desta data.

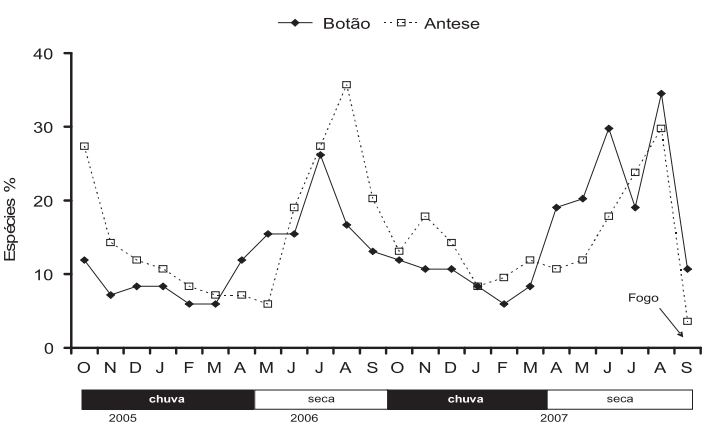

A

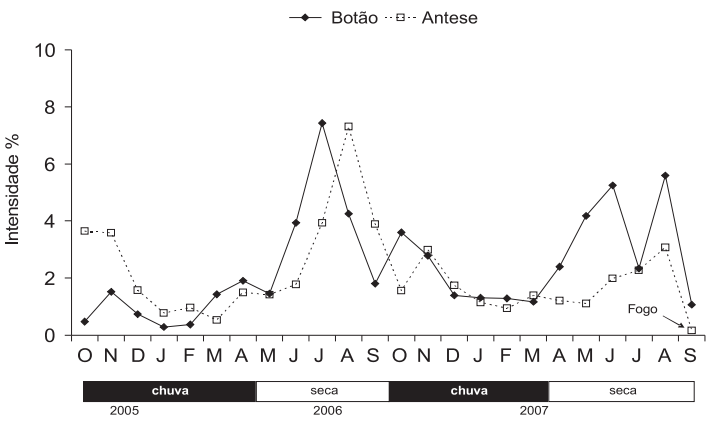

$2005 / 2006$

Floração

$2006 / 2007$
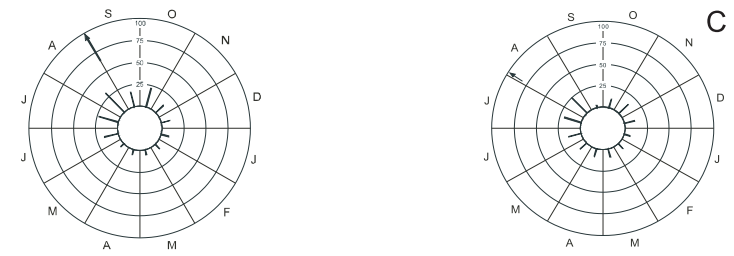

Figura 3. Porcentagem de atividade (A), e de intensidade (B) de floração no PESA, Barra do Garças, MT, Brasil. Histograma circular de freqüência relativa mensal de espécies em floração (C); a seta indica a data média de ocorrência da fenofase e o comprimento do vetor, a concentração das espécies em torno desta data. 
antese foi correlacionado negativa e significativamente com precipitação para os dois meses anteriores ao evento $(\mathrm{p}<$ $0,01)$ e com o fotoperíodo para o mês do evento e para os dois meses anteriores (Tab. 2). Ao longo do período de estudo, a floração apresentou um padrão de distribuição temporal mais contínuo, refletido pelos baixos coeficientes de concentração encontrados. A data média da floração (01/08/07) foi antecipada 29 dias (30/08/06) em relação ao primeiro ano $(F=4,87 ; \mathrm{p}=0,03)$ (Fig. 3C e Tab. 3).

O pico da fenofase fruto imaturo foi no final da estação seca (set/06 e ago/07) e precedeu o pico de frutos maduros que ocorreu no início da estação chuvosa nos dois anos estudados (out/05 e out/06) (Fig. 4A, B). Um número reduzido de espécies $(9,5 \%)$ contribuiu fortemente para a distribuição de frutos maduros ao longo do ano em função da abundância $(44,1 \%$ dos indivíduos monitorados). Foram elas, em ordem decrescente de abundância, Buchenavia tomentosa, Ouratea spectabillis, Davilla elliptica, Myrcia multiflora, Byrsonima coccolobifolia, Mouriri elliptica, Mezilaurus crassiramea e Licania humilis (Tab. 1). A frutificação (frutos maduros) foi correlacionada negativa e significativamente com a precipitação e fotoperíodo do segundo mês anterior (Tab. 2). Por outro lado, a correlação entre temperatura e número de espécies frutificando foi positiva e significativa no mês do evento $\left(\mathrm{r}_{\mathrm{s}}=0,56 ; \mathrm{p}<0,01\right)$ e no mês anterior
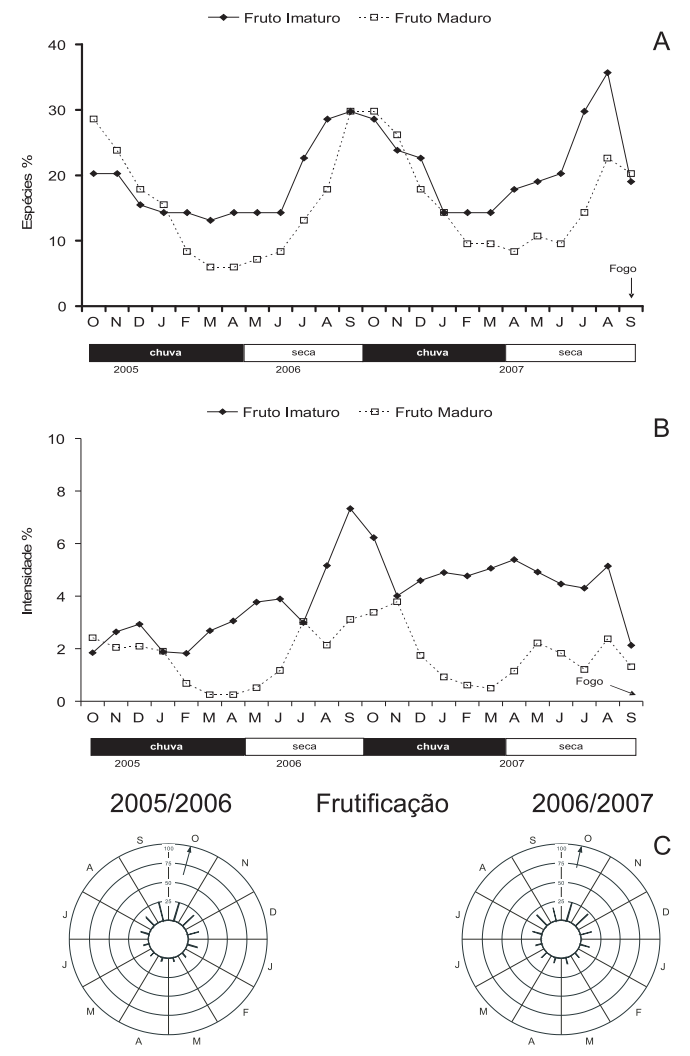

Figura 4. Porcentagem de atividade (A), e de intensidade (B) de frutificação no PESA, Barra do Garças, MT, Brasil. Histograma circular de freqüência relativa mensal de espécies em frutificação (C); a seta indica a data média de ocorrência da fenofase e o comprimento do vetor, a concentração das espécies em torno desta data. $\left(r_{\mathrm{s}}=0,40 ; \mathrm{p}=0,05\right)$. As datas médias encontradas nos dois anos de estudo foram significativas (teste Rayleigh (z); $\mathrm{p}<$ $0,01)$ e não houve diferença significativa dessas datas entre os anos de observação $(F=0,01 ; \mathrm{p}=0,94)$. Além disso, os coeficientes de concentração (r) foram baixos (Fig. 4C e Tab. $3)$, indicando fraca sazonalidade.

Sessenta espécies $(71,4 \%)$ apresentaram frutos zoocóricos e $24(28,6 \%)$ apresentaram frutos anemocóricos, não sendo observadas espécies com diásporos dispersos por outros vetores (Tab. 1). As espécies anemocóricas frutificaram principalmente durante o período seco, com pico de frutificação em agosto e setembro (Fig. 5A). O número mensal de espécies anemocóricas produzindo frutos foi correlacionado negativa e significativamente com a precipitação que ocorreu nos dois meses anteriores ao evento fenológico. Houve também correlação positiva e significativa com a temperatura do mês do evento e com fotoperíodo dos dois meses anteriores ao evento (Tab. 2). Essa foi a fenofase mais sazonal observada no PESA com as espécies frutificando de forma muito concentrada (altos coeficientes de concentração - r) ao redor da data média, a qual ocorreu na primeira quinzena de setembro nos dois anos de observação (Fig. 5B e Tab. 3).

Ao longo dos dois anos de estudo, em todos os meses, foram observadas espécies zoocóricas produzindo frutos maduros, mas foi durante o mês de outubro, tanto em 2005

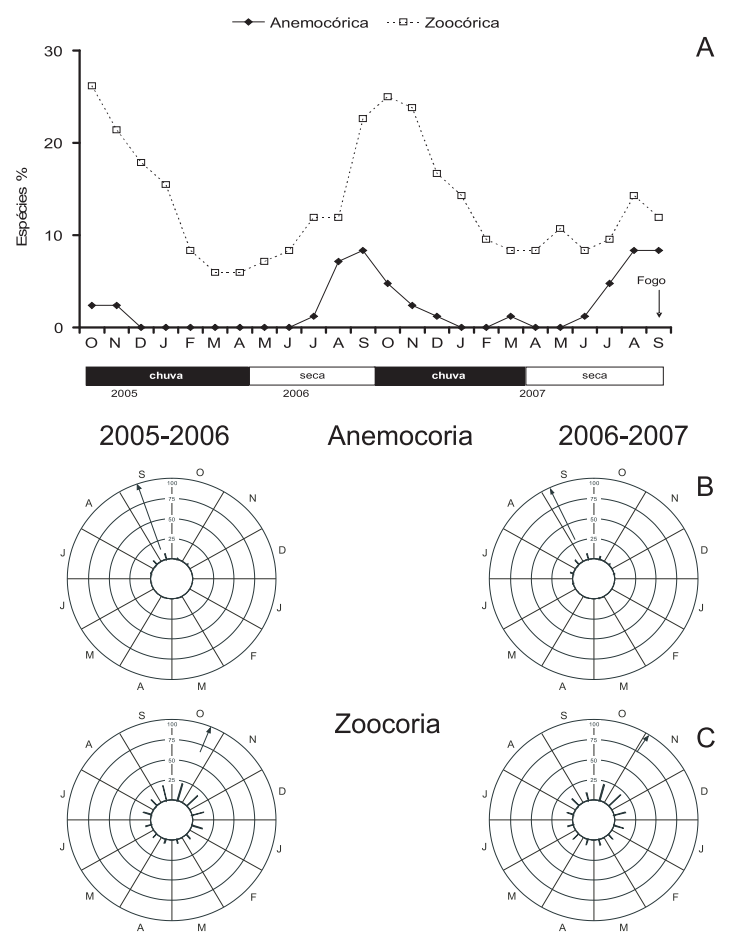

Figura 5. Porcentagem mensal de espécies arbóreas frutificando segundo a síndrome de dispersão no cerrado sentido restrito do PESA (A), Barra do Garças, MT, Brasil. Histograma circular de freqüência relativa mensal de espécies anemocóricas (B) e zoocóricas (C); a seta indica a data média de ocorrência da fenofase e o comprimento do vetor, a concentração das espécies em torno desta data. 


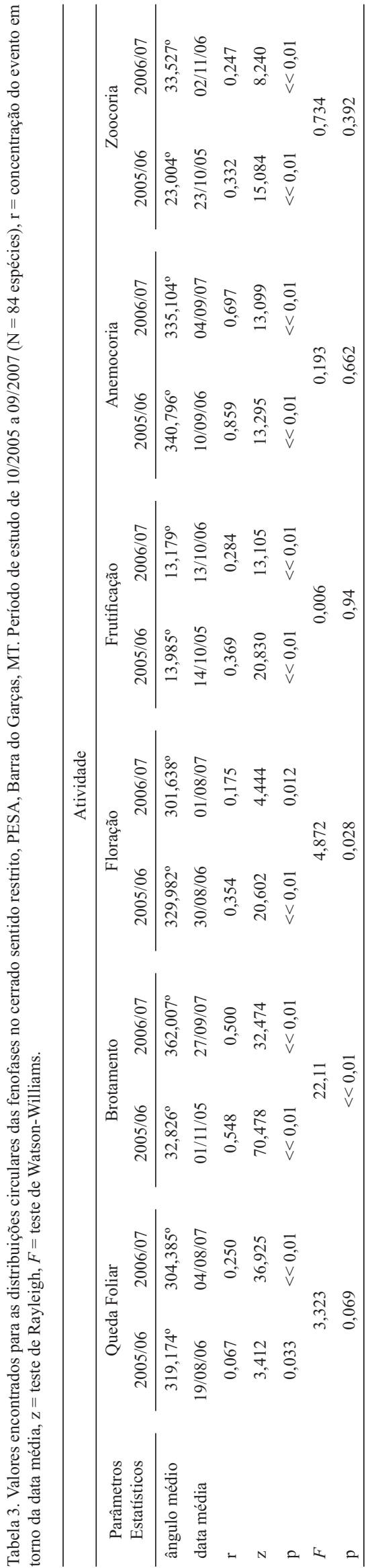

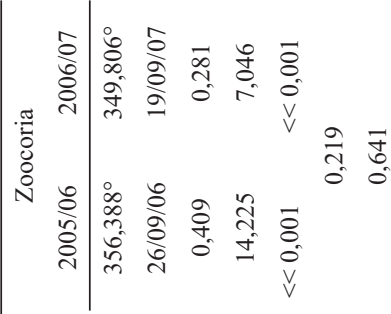

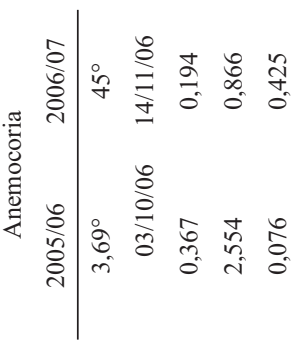

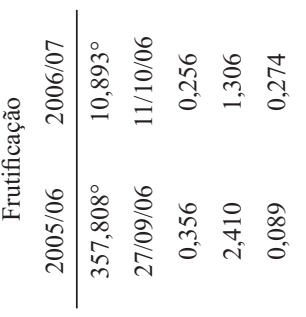

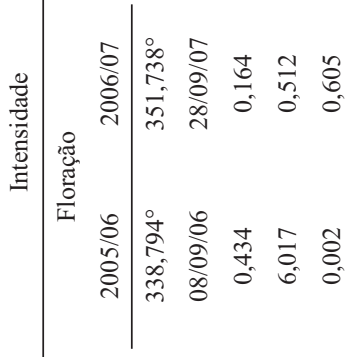

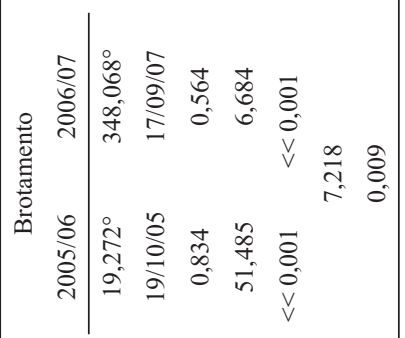

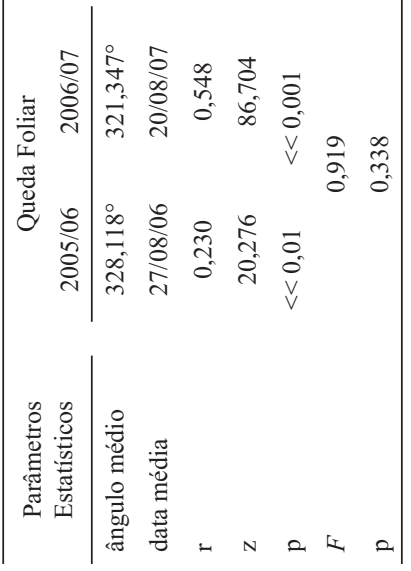


quanto em 2006, que foi observado maior número de espécies zoocóricas em frutificação (Fig. 5A). O número mensal de espécies zoocóricas em frutificação foi correlacionado negativa e significativamente com a precipitação e fotoperíodo do segundo mês anterior e positivamente com a temperatura do mês do evento e do primeiro mês anterior (Tab. 2). A frutificação das espécies zoocóricas foi distribuída de forma aproximadamente contínua ao longo dos dois anos de observação demonstrando fraca sazonalidade indicada pelos baixos coeficientes de concentração (r) (Fig. 5C e Tab. 3).

\section{Discussão}

A mais notável característica fenológica observada na comunidade arbórea do cerrado no PESA foi a forte sazonalidade relacionada com as variações anuais da precipitação e temperatura refletidas na intensidade da queda foliar e brotamento da comunidade e frutificação de espécies anemocóricas.

Fenologia vegetativa - Nossos resultados indicaram predomínio de espécies decíduas ou brevidecíduas no cerrado do PESA, o que está de acordo com o esperado para um ambiente com restrições hídricas sazonais (Kikusawa 1991). Esse padrão diferiu do que foi encontrado para uma área de cerrado no Brasil Central (Gouveia \& Felfili 1998) e savanas dos Lhanos na América do Sul (Sarmiento et al. 1985), onde as espécies foram consideradas predominantemente sempre-verdes, mas foi semelhante ao padrão observado nas savanas africanas (Bie et al. 1998) e australianas (Williams et al. 1997), onde foram encontradas principalmente espécies decíduas. Nos cerrados do Brasil, esses padrões ainda são pouco conhecidos, pois apenas alguns estudos recentes têm adotado critérios claros para definição dos grupos vegetativos (Franco 2002; Franco et al. 2005; Lenza \& Klink 2006; Araújo \& Haridasan 2007) o que pode ter levado a conclusões divergentes sobre as proporções dos grupos vegetativos nas comunidades estudadas no Brasil Central. Aparentemente, quanto mais severas forem as restrições hídricas impostas pela sazonalidade climática maiores as proporções de espécies decíduas observadas nas comunidades. Se a sazonalidade na umidade é acentuada, espécies perdendo as folhas de forma mais concentrada na estação seca são favorecidas e ilustram o mecanismo de escape ao estresse hídrico (O’Brien et al. 2008).

Um padrão fenológico consistente que emergiu das nossas análises foi que, em todos os meses, foram observadas espécies perdendo folhas, o que resultou em valores de $r$ baixos e um padrão aproximadamente contínuo de queda foliar. No entanto, quando consideramos a intensidade das fenofases, a comunidade apresentou maior sazonalidade, sendo que o maior impacto na fenologia vegetativa foi causado pelas espécies mais abundantes, na maioria, decídua ou brevidecídua. A maior intensidade de queda foliar observada no segundo ano pode ter sido causada pela severidade da estação seca em 2007. Nesse ano, a seca começou mais cedo sendo mais longa e quente que no ano anterior. Soma-se a isso, a influência do fogo que atingiu a área em setembro de 2007, causando a abscisão foliar na quase totalidade das espécies e indivíduos. A queda foliar ocorreu principalmente no final da estação seca, o que fez com que o aspecto da vegetação mudasse para decíduo, e foi seguida pelo brotamento. Tanto para áreas core de cerrado no Brasil Central (Gouveia \& Felfili 1998; Lenza \& Klink 2006) quanto para áreas mais periféricas da distribuição do cerrado (Mantovani \& Martins 1988; Batalha et al. 1997 - ambos em São Paulo) e áreas disjuntas (Miranda 1995 - no Pará), o padrão fenológico vegetativo foi similar com o pico de espécies perdendo folhas no final da estação seca e brotamento no início da estação chuvosa. A diminuição da quantidade de água nas camadas mais superficiais do solo, no início da estação seca, tem sido associada com a queda foliar devido ao declínio do potencial hídrico, o qual induziria essa fenofase (Corlett 1993). Apesar de, em florestas tropicais, experimentos com irrigação durante a estação seca demonstrarem pouco impacto sobre o padrão de queda foliar (Wright \& Cornejo 1990), a reidratação dos ramos durante a queda das folhas, controlada primariamente por fatores endógenos (Reich 1995), é um pré-requisito para a subseqüente abertura das gemas vegetativas e botões florais (Borchert 1996).

$\mathrm{O}$ adiantamento de cerca de 30 dias na data média do brotamento no segundo ano pode ter sido favorecido pela variação interanual de temperatura. $\mathrm{O}$ pico de temperatura média mensal $\left(26,6^{\circ} \mathrm{C}\right)$ registrado em 2006 ocorreu exatamente 1 mês antes daquele registrado em $2005\left(26,4{ }^{\circ} \mathrm{C}\right.$ em setembro), o que coincidiu com o brotamento antes do início das chuvas. Tem sido sugerido que a elevação da temperatura pode ser um fator indutor do brotamento em árvores tropicais, por meio da estimulação do desenvolvimento de brotos apicais pré-dormentes (Morellato et al. 1989). Além disso, nas espécies lenhosas do cerrado, a reidratação que precede o brotamento resulta de ajustes na demanda e suprimento de água da planta, os quais são regulados pela redução da área foliar (como resultado da perda de folhas), abertura estomática, profundidade do sistema radicular e reservatório interno de água (Franco 2002).

Fenologia reprodutiva - Nossos dados indicaram floração anual para a maioria das espécies e esse padrão é comumente descrito para espécies lenhosas do cerrado (Felfili et al. 1999; Lenza \& Klink 2006). As espécies que não floresceram no período de observação sugerem padrões supra-anuais de floração ou podem ter sido representadas por indivíduos que não atingiram a fase reprodutiva. Esse é um fato comumente registrado em estudos fenológicos de comunidades vegetais (Mantovani \& Martins 1988; Morellato et al. 1989; Miranda 1995; Griz \& Machado 2001; Costa et al. 2004). No entanto, segundo Newstrom et al. (1994), a maioria das espécies tropicais não apresenta, de fato, padrões anuais de floração. Para muitas espécies é possível registrar a ocorrência (presença) de flores todos os anos, mas existe muita variação interanual na quantidade de flores produzidas de forma que, em certos anos, a produção de flores pode ser tão reduzida que, na prática, 
aquela espécie que floresceu discretamente não contribui de maneira efetiva com recursos para a comunidade. Este parece ser o caso de Byrsonima coccolobifolia e Davilla elliptica que produziram muitas flores apenas no primeiro ano de observação e Mezilaurus crassiramea e Kielmeyera rubriflora que floresceram intensamente apenas no segundo ano.

Ao longo de todo ano, foi possível observar espécies arbóreas em flor no PESA, mas para a maioria delas, essa fenofase ocorreu na estação seca, após a abscisão foliar. A floração durante a seca parece ser um padrão comum da vegetação arbórea do cerrado (Miranda 1995; Gouveia \& Felfili 1998, Batalha \& Mantovani 2000; Lenza \& Klink 2006; Tannus et al. 2006). Segundo Oliveira (2008), os padrões fenológicos reprodutivos de plantas lenhosas do cerrado são menos dependentes das restrições sazonais impostas pelo clima. Nossos resultados mostrando que a floração se correlacionou negativamente com a precipitação reforçam essa idéia. O encadeamento seqüencial de eventos fenológicos, vegetativos e reprodutivos, durante a seca é um padrão típico de espécies arbóreas decíduas de cerrado (Miranda 1995), sugerindo que a floração seja induzida por reidratação devido à redução da transpiração decorrente da queda foliar (Borchert 1994).

Assim como ocorreu para floração, a maioria das espécies frutificou anualmente. No entanto, quando observamos o número de indivíduos em frutos, detectamos que considerar o padrão de freqüência anual pode ser um equívoco para muitas espécies. Por exemplo, no primeiro ano de observação no PESA, apenas alguns indivíduos de espécies consideradas anuais como Ouratea spectabillis e Buchenavia tomentosa produziram poucos frutos, e na prática, nesses anos de baixa produção, tais espécies não devem representar recursos importantes para a fauna.

Entre os padrões de frutificação encontrados no cerrado do PESA, a presença de frutos durante todo o período de estudo, a fraca sazonalidade dessa fenofase, a zoocoria predominante na comunidade e os distintos padrões de frutificação entre os modos de dispersão são similares aos que têm sido encontrados para outras áreas de cerrado (Miranda 1995; Gouveia \& Felfili 1998; Batalha \& Mantovani 2000; Oliveira \& Gibbs 2000; Batalha \& Martins 2004; Lenza \& Klink 2006; Tannus et al. 2006) e sugerem que plantas anemocóricas e zoocóricas estão sob influência de diferentes fatores. A produção contínua de frutos na comunidade pode ser considerada uma evidência que essa fenofase apresenta certa independência de fatores abióticos. No entanto, os picos de frutificação no início da estação chuvosa sugerem que essa época é melhor para dispersão dos diásporos nessa comunidade. A eficácia dos mecanismos de dispersão deve estar ligada à sincronização da germinação com o início da estação chuvosa (Frankie et al. 1974; Oliveira 2008). Segundo Felfili et al. (1999), a maturação e a dispersão dos frutos na estação seca e transição seca-chuva aumentam as chances de germinação e crescimento de plântulas, quando as sementes são beneficiadas pela umidade e abundância de nutrientes liberados a partir da decomposição da serapilheira acumulada na estação seca. Além disso, as plântulas que emergem no início da estação chuvosa encontram condições ambientais mais favoráveis ao estabelecimento, pois poderão desenvolver sistemas radiculares profundos antes da próxima seca. Nossos resultados reforçam a hipótese de que a fenologia reprodutiva das plantas que vivem em habitats sazonais tem sido moldada para sincronizar a maturação dos frutos e a liberação das sementes com a época mais favorável para o crescimento e a sobrevivência das plântulas.

$\mathrm{O}$ alto coeficiente de concentração (r) de espécies anemocóricas que frutificaram na estação seca pode estar relacionado às condições favoráveis para dispersão dos diásporos. Esses padrões têm sido encontrados tanto para fisionomias savânicas (Batalha \& Mantovani 2000; Oliveira \& Gibbs 2000; Batalha \& Martins 2004) como para matas de galeria e ciliares (Oliveira \& Moreira 1992; Gouveia \& Felfili 1998; Reys et al. 2005). A dispersão de diásporos anemocóricos é favorecida durante períodos mais secos em regiões com clima sazonal, uma vez que a baixa umidade do ar promove a abertura dos frutos e o aumento na velocidade dos ventos e redução da cobertura das folhas na vegetação facilitam a dispersão dos diásporos (Mantovani \& Martins 1988; Batalha \& Mantovani 2000; Oliveira 2008).

Nesse trabalho encontramos padrões sazonais, sendo que as mudanças fenológicas foram concentradas nos três meses mais secos e quentes do ano (ago-out), caracterizando a transição entre as estações seca e chuvosa como o período de maior atividade fenológica, tanto vegetativa quanto reprodutiva da comunidade. A sincronização fenológica observada na comunidade sugere que os padrões das espécies individualmente foram ajustados pela pronunciada estacionalidade do ambiente. As fenofases parecem estar sob o controle dos suprimentos internos de água das árvores, no entanto, aparentemente, a disponibilidade de água não é um fator limitante e sim um fator seletivo. As fenofases vegetativas foram relacionadas mais fortemente com variáveis abióticas, principalmente precipitação (queda de folhas) e temperatura (brotamento), enquanto que as fenofases reprodutivas foram menos influenciadas por esses fatores. A acentuada perda das folhas observada na comunidade provavelmente permitiu a reidratação das plantas, o que pode ter favorecido o brotamento, estimulado pela elevação da temperatura que ocorreu na fase de transição entre estações seca e chuvosa. $\mathrm{O}$ fluxo de folhas novas possivelmente aumentou a eficiência fotossintética das plantas, provendo energia necessária para o pico de floração e frutificação subseqüentes observados na comunidade. Como esperado, a frutificação de espécies anemocóricas foi a única fenofase reprodutiva fortemente correlacionada com condições abióticas, sendo que a deiscência dos frutos e dispersão das sementes ocorreu no auge da estação seca, quando as condições ambientais foram mais favoráveis à dispersão de diásporos alados e plumosos. A fenologia reprodutiva das espécies lenhosas do cerrado no PESA parece estar sincronizada para que a maturação dos 
frutos e a liberação das sementes ocorram no início da estação chuvosa, época mais favorável para o crescimento e a sobrevivência das plântulas.

\section{Agradecimentos}

Agradecemos à Michele Ribeiro e Ana Cristina Silva pelo auxílio nos trabalhos de campo, aos Drs. Eddie Lenza, Roberto Leung e Frederico Takahashi pela leitura crítica do manuscrito e auxílio nas análises estatísticas, ao Domingos Pedroni pela revisão do abstract, à CAPES pela bolsa de Mestrado concedida para a primeira autora, à FAPEMAT pelo apoio financeiro, à INFRAERO por fornecer os dados climáticos, à SEMA-MT pela permissão para a realização de estudos no Parque Estadual da Serra Azul.

\section{Referências bibliográficas}

Araújo, J.F. \& Haridasan, M. 2007. Relação entre deciduidade e concentração foliares de nutrientes em espécies lenhosas do cerrado. Revista Brasileira de Botânica 30(3): 533-542.

Barbosa, M.M. 2006. Florística e fitossociologia de Cerrado sentido restrito no Parque Estadual da Serra Azul, Barra do Garças, MT. Dissertação de Mestrado. Cuiabá. Universidade Federal de Mato Grosso.

Batalha, M.A.; Aragaki, S. \& Mantovani, W. 1997. Variações fenológicas das espécies do cerrado em Emas, Pirassununga, São Paulo. Acta Botanica Brasilica 11(1): 61-78

Batalha, M.A. \& Mantovani, W. 2000. Reproductive phenological patterns of cerrado plant species at the Pé-de-Gigante Reserve (Santa Rita do Passa Quatro, SP, Brazil): a comparison between the herbaceous and woody floras. Revista Brasileira de Biologia 60(1): 129-145.

Batalha, M.A. \& Martins, F.R. 2004. Reproductive phenology of the cerrado plant community in Emas National Park. Australian Journal of Botany 52(2): 149-161.

Bie, S.; Ketner, P.; Paasse, M. \& Geerling, C. 1998. Woody plant phenology in the West Africa savanna. Journal of Biogeography 25(5): 883-900.

Borchert, R. 1994. Soil and stem water storage determine phenology and distribution of tropical dry forest trees. Ecology 75(5): 1437-1449.

Borchert, R. 1996. Phenology and flowering periodicity of Neotropical dry forest species: evidence from herbarium collections. Journal of Tropical Ecology 12(1): 65-80.

Boulter, S.L.; Kitching, R.L \& Howlett, B.G. 2006. Family, visitors and the weather: patterns of flowering in tropical rain forests of northern Australian. Journal of Ecology 94(2): 369-382.

Corlett, R.T. 1993. Reproductive phenology of Hong Kong shrubland. Journal of Tropical Ecology 9(4): 501-510.

Costa, I.R.; Araújo, F.S. \& Lima-Verde, L.W. 2004. Flora e aspectos autoecológicos de um encrave de Cerrado na Chapada de Araripe, Nordeste do Brasil. Acta Botanica Brasilica 18(4): 759-770.

Felfili, J.M.; Silva-Junior, M.C.; Dias, B.J. \& Rezende, A.V. 1999. Estudo fenológico de Stryphnodendron adstringens (Mart.) Coville no cerrado sensu stricto da Fazenda Água Limpa no Distrito Federal, Brasil. Revista Brasileira de Botânica 22(1): 83-90.

FEMA - Fundação Estadual do Meio Ambiente - MT. 2000. Diagnóstico ambiental do Parque Estadual da Serra Azul. Barra do Garças. SEMA.

Fournier, L.A. 1974. Un método cuantitativo para la medición de características fenológicas en árboles. Turrialba 24(4): 422-423.

Franco, A.C. 2002. Ecophysiology of woody plants. Pp. 178-197. In: P.S. Oliveira \& R.J Marquis (eds.). The cerrados of Brazil: ecology and natural history of a neotropical savanna. New York, Columbia University Press.

Franco, A.C.; Bustamante, M.M.; Caldas, L.S.; Goldstein, G.; Meinzer, F.C.; Kozovits, A.R.; Rundel, P. \& Coradin, V.T.R. 2005. Leaf functional traits of Neotropical savanna trees in relation to seasonal water deficit. Trees Structure and Function 19(3): 326-335.

Frankie, G.W.; Baker, H. \& Opler, P. A. 1974. Comparative phenological studies of trees in tropical wet and dry forest in the lowlands of Costa Rica. Journal of Ecology 62(3): 881-919.
Gouveia, G.P. \& Felfili, J.M. 1998. Fenologia de comunidades de cerrado e de mata de galeria no Brasil Central. Revista Árvore 22(4): 443-450.

Griz, L.M.S. \& Machado, I.C.S. 2001. Fruiting phenology and seed dispersal syndromes in caatinga, a tropical dry forest in the northeast of Brazil. Journal of Tropical Ecology 17(2): 303-321.

Kikusawa, K. 1991. A cost-benefit analysis of leaf habit and leaf longevity of trees and their geographical pattern. American Naturalist 138(5): $1250-1263$

Kovach, W.L. 2007. Oriana for Windows, V.2.02e. Anglesey, Wales, UK, Kovach Computing Services.

Lenza, E. \& Klink, C.A. 2006. Comportamento fenológico de espécies lenhosas em um cerrado sentido restrito de Brasília, DF. Revista Brasileira de Botânica 29(4): 627-638.

Mantovani, W. \& Martins, F.R. 1988. Variações fenológicas das espécies do cerrado da Reserva Biológica de Moji Guaçu, Estado de São Paulo. Revista Brasileira de Botânica 11(1/2): 101-102.

Marchioretto, M.S.; Mauhs, J. \& Budke, J.C. 2006. Fenologia de espécies arbóreas zoocóricas em uma floresta psamófila no sul do Brasil. Acta Botanica Brasilica 21(1): 193-201.

Miranda, I.S. 1995. Fenologia do estrato arbóreo de uma comunidade de cerrado em Alter-do-Chão, PA. Revista Brasileira de Botânica 18(2): 235-240.

Morellato, L.P.C.; Rodrigues, R.R.; Leitão Filho, H.F. \& Joly, C.A. 1989. Estudo comparativo da fenologia de espécies arbóreas de floresta de altitude e floresta mesófila semidecídua na Serra do Japi, Jundiaí, São Paulo. Revista Brasileira de Botânica 12(1): 85-98.Morellato, L.P.C.; Talora, D.C.; Takahasi, A.; Romera, E.C. \& Ziparro, V.B. 2000. Phenology of Atlantic Rain Forest trees: a comparative study. Biotropica 32(4b): 811-823.

Munhoz, C.B.R. \& Felfili, J.M. 2005. Fenologia do estrato herbáceosubarbustivo de uma comunidade de campo sujo, Fazenda Água Limpa, Distrito Federal, Brasil. Acta Botanica Brasilica 19(4): 979-988.

Munhoz, C.B.R. \& Felfili, J.M. 2007. Reproductive phenology of an herbaceous-subshrub layer of a Savannah (Campo Sujo) in the Cerrado Biosphere Reserve I, Brazil. Brazilian Journal of Biology 67(2): 299-307.

Newstrom, L.E.; Frankie, G.W. \& Baker, H.G. 1994. A new classification for plant phenology based on flowering in lowland tropical rain forest trees at La Selva, Costa Rica. Biotropica 26(2): 141-159.

O’Brien, J.J.; Oberbauer, S.F.; Clark, D.B. \& Clark, D.A. 2008. Phenology and stem diameter increment seasonality in a Costa Rican wet tropical forest. Biotropica 40(2): 151-159.

Oliveira, P.E. \& Gibbs, P.E. 2000. Reproductive biology of woody plants in a cerrado community of the central Brazil. Flora 195(4): 311-329.

Oliveira, P.E. \& Moreira, A.G. 1992. Anemocoria em espécies de cerrado e de mata de galeria. Revista Brasileira de Botânica 15(2): 163-174.

Oliveira, P.E. 2008. Fenologia e biologia reprodutiva das espécies de cerrado.Pp. 275-290. In: S.M. Sano, S.P. Almeida \& J.F. Ribeiro (eds.). Cerrado: ecologia e flora. Brasília, EMBRAPA.

Oliveira, R.S.; Bezerra, L.; Davidson, E.A.; Pinto, F.; Klink, C.A.; Nepstad, D.C. \& Moreira, A. 2005. Deep root function in soil water dynamics in cerrado savannas of central Brazil. Functional Ecology 19(4): 574-581.

Pijl, L. van der. 1982. Principles of dispersal in higher plants. Berlin, Springer - Verlag.

Poulin, B.; Wright, S.J.; Lefebvre, G. \& Calderón, O. 1999. Interspecific synchrony and asynchrony in the fruiting pheonologies of congeneric bird-dispersed plants in Panama. Journal of Tropical Ecology 15: 213-227.

Reich, P.B. 1995. Phenology of tropical forests: patterns, causes, and consequences. Canadian Journal of Botany 73(2): 164-174.

Reys, P.; Galetti, M.; Morellato, L.P. \& Sabino, J. 2005. Fenologia reprodutiva e disponibilidade de frutos de espécies arbóreas em mata ciliar no Rio Formoso, Mato Grosso do Sul. Biota Neotropica 5(2): 309-318. http://www.scielo.br/scielo.php?script=sci arttext\&pid $=$ S1676-06032005000300021\&lng $=$ en\&nrm=iso (Acesso em: 26/02/2009).

Sarmiento, G.; Goldstein, G. \& Meinzer, F.M. 1985. Adaptive strategies of woody species in neotropical savannas. Biological Reviews 60(3): 315-355. 
Stevenson, P.R.; Castellanos, M.C.; Cortés, A.I. \& Link, A. 2008. Flowering patterns in a seasonal tropical lowland forest in western Amazonia. Biotropica 40(5): 559-567.

Tannus, J.L.S.; Assis, M.A. \& Morellato, L.P. 2006. Fenologia reprodutiva em campo sujo e campo úmido numa área de cerrado no sudeste do Brasil, Itirapina-SP. Biota Neotropica 6(3) http://www.scielo.br/scielo php?script $=$ sci_arttext\&pid=S1676-06032006000300008\&lng=en\&n $\mathrm{rm}=$ iso (Acesso em: 26/02/2009).

Williams, R.J.; Myers, B.A.; Muller, W.J.; Duff, G.A. \& Eamus, D. 1997.
Leaf phenology of woody species in a north Australian tropical savanna. Ecology 78(8): 2542-2558.

Wright, S.J. \& Cornejo, F.H. 1990. Seasonal drought and leaf fall in a tropical forest. Ecology 71(3): 1165-1175.

Yamamoto, L.F.; Kinoshita, L.S. \& Martins, F.R. 2007. Síndromes de polinização e dispersão em fragmentos da Floresta Estacional Semidecídua Montana, SP, Brasil. Acta Botanica Brasilica 21(3): 553-567.

Zar, J.H. 1998. Biostatistical analysis. New Jersey, Prentice-Hall. 